\title{
Fireproofing of domestic upholstered furniture: Migration of flame retardants and potential risks
}

\author{
Mohammed Lounis ${ }^{\mathrm{a}}$, Stéphane Leconte ${ }^{\mathrm{a}, *}$, Christophe Rousselle ${ }^{\mathrm{a}}$, Luc P. Belzunces ${ }^{\mathrm{b}}$, \\ Valérie Desauziers ${ }^{\mathrm{c}}$, José-Marie Lopez-Cuesta ${ }^{\mathrm{c}}$, Jean Mario Julien ${ }^{\mathrm{d}}$, Dominique Guenot ${ }^{\mathrm{e}}$, \\ Damien Bourgeois ${ }^{\mathrm{f}}$
}

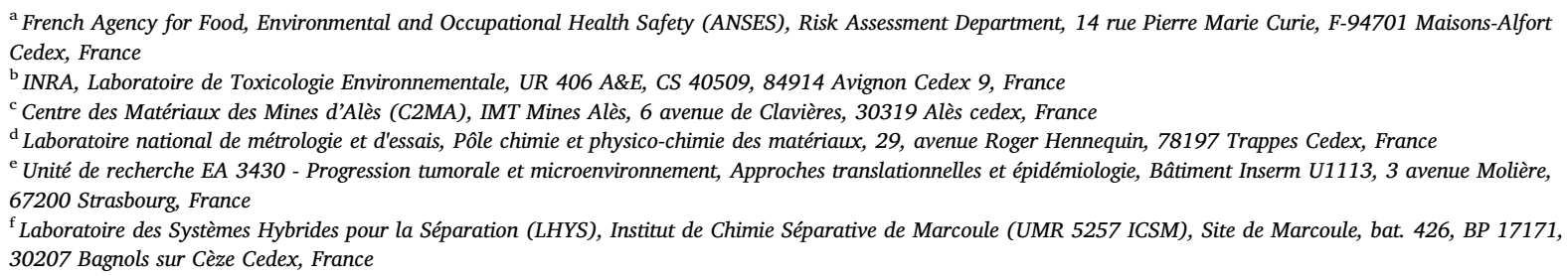

\begin{abstract}
A B S T R A C T
Flame retardants (FRs) are widely incorporated in polyurethane foams to decrease their fire reaction. Currently, the risks associated with the use of FRs in domestic upholstered furniture (UF) are evaluated according to FRs volatility and potency to be emitted into the atmosphere. However, exposure via contact and dermal penetration, mediated by sweat, has not been considered so far. Our study provides an identification of the latest-generation of FRs most commonly used in UF, and an evaluation of their potency to migrate into artificial sweat. First of all, an extensive literature search, along with surveys with professionals, led to the identification of twenty-two FRs and synergists commonly used in France and Europe. Then, migration into artificial sweat of various FRs embedded into synthetic or commercially available polymer matrix was studied and evidenced. These results were analysed in the light of their potential effects on human health and the environment. Based on the migration's data, it is not possible to clearly rule out potential effects of FRs on human and environment health. Therefore, the authors consider that the use of FRs in domestic upholstery does not seem to be justified due to potential risks and a lack of clear benefits.
\end{abstract}

Keywords:

Flame retardant

Upholstered furniture

Domestic fire

Polyurethane foam

Migration

Risk assessment

\section{Introduction}

The prevention of domestic fires is an important public health issue. In 2011 in France, 81,027 home fires were recorded and left about 800 people dead and 10,000 injured [1]. The causes of these fires are multiple, including electrical failures and cigarettes. The contribution of each item to the initiation and/or spread of fires is still the subject of various studies and debates. Upholstered furniture (UF) (sofas, chairs, mattresses) is generally seen as a major factor in the spread of fires. As a consequence, the fireproofing of UF has been mandatory and regulated in the European Union for a long time in several places, especially for the seats of public buildings (theatres, cinemas, hospitals, prisons, etc.) and those of cars, trains, and planes [2].

To assess the flammability of UF, fire resistance is determined for a whole UF piece, according to standard guidelines based on different criteria and ignition sources (e.g. burning cigarette test, small flame or match test, flame spread test, Crib 5 test) [3]. Although a lot of UF may comply with relevant flammability tests without further treatment, the use of flame retardants (FRs) is often necessary and is currently regarded as the best available solution to reduce the number of domestic fires. The use of several FRs in UF has already been evaluated by the scientific community [4]. Polybrominated diphenyl ethers (PBDEs) and organophosphorus esters, especially tricresyl phosphate (TMPP), were proven to be toxic [5], leading to the appraisal of health concerns for the general population exposed to these ubiquitous substances [6-9]. TMPP and PBDEs are merely incorporated into the polymer matrices, with no covalent bond [10]. They are volatile enough to be released into the atmosphere and stable enough to remain in the environment

\footnotetext{
* Corresponding author.

E-mail address: Stephane.leconte@anses.fr (S. Leconte).
} 
for years without any significant degradation. Therefore, they are systematically detected in indoor atmospheres and/or dust [11]. Two studies by Stapleton et al. $[10,12]$ showed a high detection frequency for some FRs (TPHP, TDCPP, HBCDD, TCIPP) in dust from homes in the Boston area of the United States. Two other studies by Ali et al. [13,14] showed that there was a significant positive correlation $(\mathrm{p}<0.05)$ between the concentrations of certain FRs in dust from bedroom floors and concentrations in mattresses used in these rooms.

Research projects are still underway to reduce the fire risk of thermoplastic materials used in UF, and alternative FRs presented as safer are now proposed on the market [15-17]. Some of these new FRs have higher molecular weights and are therefore not expected to be emitted from UF, or at least at very low levels $[18,19]$. Other techniques, such as the grafting of the FR onto the polymer matrix, have been proposed to guarantee the safe incorporation of the FR into the UF. Inorganic substances, as well as organic salts, are not expected to be released into the atmosphere. The fireproofing of domestic UF has been mandatory in the United Kingdom (UK) since 1988, as in the state of California since 1977. The generalisation of the systematic use of FR in domestic UF is under discussion in the European Union [1]. In 2011, the French Agency for Food, Environmental and Occupational Health \& Safety (ANSES) was appointed to evaluate the benefits and risks of generalising domestic UF fireproofing by FRs. As a consequence, risks associated with recently developed FRs were studied. Human exposure to FRs used in UF can have two origins: (i) FRs that are not chemically bound to the polymer matrix may volatilise, which may lead to exposure by inhalation, and (ii) skin contact with the UF. Skin contact that may also lead to the transcutaneous passage of FRs, which is facilitated by sweat that can both extract the FR and serve as a vehicle. The first route of exposure, i.e. inhalation, is usually considered in risk assessment of FRs [20,21]. However, the second route of exposure, i.e. migration via sweat, has to our knowledge never been evaluated for fireproofed UF. Migration of chemical additives present in polymers and plastics has been the subject of various studies, but no study dedicated to the migration of FRs from UF has been reported so far [22]. We therefore developed an innovative experimental procedure to evaluate the possible migration of FRs from the polymer matrix of UF into synthetic sweat. The purpose of this article is to detail the results obtained regarding the ability of FRs to migrate from UF through sweat. First of all, the most commonly used FRs in UF in France and Europe were identified according to literature review and analysis of representative market samples. This part of the work enabled to detail the different processes by which FRs are added to the products, depending on the polymer matrix and the FR used. Then, migration studies in artificial sweat were conducted. Finally, the migration results were discussed in light of toxicological and environmental data gathered from the literature and to assess the potential risks associated with these FRs.

\section{Materials and methods}

\subsection{Collection of market samples}

Authentic market samples were provided by the French Technological Institute for Forest, Pulp, Wood in Timber \& Furniture (FCBA). They were taken from various pieces of UF that are supposed to be fireproofed and are distributed on the French market. The sampling strategy did not correspond to a statistical representation but was oriented in order to obtain different fireproofing reagents and techniques, thanks to the experience and know-how of FCBA and customer information provided by the suppliers. Five different samples of coated fabric, including one of synthetic leather, four different samples of foams, and three different samples of cotton cloth were thus collected (Table 1). No precise information was given on the coated fabric and foam samples; the cotton clothes were said to have been prepared according to a reactive grafting process, but the exact details were kept confidential by the manufacturer.

\subsection{Chemical analysis of UF samples}

Samples were analysed to determine the nature and quantitative content of the FR in the different polymer matrices. Elemental analyses were carried out directly on cross-sections cuts, obtained from the UF, by energy-dispersive X-ray spectrometry (X-EDS) using a FEI QUANTA FEG 200 environmental scanning electron microscope (ESEM) equipped with a gaseous secondary electron detector (GSED). The experiments were performed at $100 \mathrm{~Pa}$ with an accelerating voltage of $15 \mathrm{kV}$. In some cases, structure confirmation was obtained only later on through a comparison with known substances during migration studies (vide infra).

\subsection{Preparation of synthetic samples}

Polyamide 6 (Aquamid $6 \mathrm{AV}$ ), polypropylene (PPH 10,012), polyethylene terephthalate, resorcinol diphosphate, melamine pyrophosphate, a decabromodiphenyl ether $/ \mathrm{Sb}_{2} \mathrm{O}_{3}$ mixture $(3 / 1$, as a dry blend), polyol and toluene diisocyanate were obtained as samples from different industrial suppliers (Solvay, Reseko, Bluestar, ICL-IP, Thor). Technical-grade Triphenyl phosphate (TPHP), Tris(2-chloro-1-isopropyl) phosphate (TCIPP) and Tris[2-chloro-1-chloromethyl)ethyl] phosphate (TDCPP) were purchased from Sigma-Aldrich and used without further purification. Analytical-grade sodium chloride, sodium hydroxide, DL-lactic acid and urea were purchased from Fluka.

Polyurethane (PU) foams incorporating various FRs were prepared by mixing a polyol-based resin with toluene diisocyanate. The resin was mixed with toluene diisocyanate for $20 \mathrm{~s}$, then foams were polymerised in $45 \times 36 \times 1 \mathrm{~cm} 3$ moulds. Detailed PU foam formulations are given in Table S1. Three substances with flame retarding properties were used: TPHP, TCIPP and TDCPP. Polymer film samples with a composition similar to that expected for polymer fibres were prepared by extrusion-calendering. A laboratory twin screw extruder (Clextral BC 21) with an L/D ratio of 36:1 was used. According to a preliminary test, the barrel temperature in the feeding and final zones was $50^{\circ} \mathrm{C}$ and that in the second zone was $80^{\circ} \mathrm{C}$. The three heating zones were independently electrically heated and air-cooled. The feed rate varied according to the weight of the sample and the screw speed was $40 \mathrm{rpm}$. Feed moisture varied from $16 \%$ to $30 \%$. The extrusion-calendering process was carried out with a Haake co-extrusion system, with a diameter/length ratio of 16/25 and a compression ratio of 1:1.

\subsection{Migration studies}

The potential migration of FRs into sweat was studied using a sweat simulant that corresponded to an aqueous solution buffered at $\mathrm{pH}$ $6.50 \pm 0.05$, prepared according to the specifications of the European Standard EN 1811. It was prepared by adding $1.00 \mathrm{~g}$ urea, $5.00 \mathrm{~g}$ sodium chloride and $1.00 \mathrm{~g}$ DL-lactic acid to $1.00 \mathrm{~L}$ of deionised water. The $\mathrm{pH}$ of the resulting solution was then adjusted to 6.5 with sodium hydroxide. The migration test was performed according to the European Standard EN 1186 (initially designed for materials and articles in contact with foodstuffs). Samples collected from UF were placed against the bottom of a stainless-steel cell equipped with a press and joints so that $200 \mathrm{~cm}^{2}$ of the top surface of the sample was facing the inside of the cell. Then $200 \mathrm{~mL}$ of the sweat simulant were added to the cell, which was closed and placed in an oven for 20 days at $50^{\circ} \mathrm{C}$. All experiments were repeated three times. The FRs in the resulting sweat simulant were quantified using Gas Chromatography coupled with Mass Spectrometry (GC/MS) (TDCPP, TPHP, RDP), Gas chromatography/ flame ionization detectors (GC/FID) (RDP), high performance liquid chromatography/UV detectors (HPLC/UV) (MP, THPC, DMPPA), ion chromatography (MP, PA-GP), ICP/MS (DBDPE, $\mathrm{Sb}_{2} \mathrm{O}_{3}$ ) or ICP/optical emission spectrometry $\left(\mathrm{Sb}_{2} \mathrm{O}_{3}\right)$. The results were corrected by 
Table 1

Compositions of the studied samples.

\begin{tabular}{|c|c|c|c|c|}
\hline Sample & Origin & Matrix & FR & $\begin{array}{l}\text { FR amount } \\
\text { (in weight \%) }\end{array}$ \\
\hline Foam-1 & Synthetic & Polyurethane (PU) & Tris(1-chloro-2-propyl) phosphate (TCIPP) & $8.5 \%$ \\
\hline Foam-2 & Synthetic & PU & Tris(1,3-dichloro-2-propyl) phosphate (TDCPP) & $8.5 \%$ \\
\hline Foam-3 & Synthetic & PU & Triphenyl phosphate (TPHP) & $8.5 \%$ \\
\hline Foam-4 & Commercial & PU & TCIPP & $3 \%$ \\
\hline Foam-5 & Commercial & PU & TCIPP & $4.5 \%$ \\
\hline Foam-6 & Commercial & PU & TCIPP & $8.7 \%$ \\
\hline Foam-7 & Commercial & PU & TCIPP & $6.5 \%$ \\
\hline \multirow[t]{2}{*}{ Coating-1 } & \multirow[t]{2}{*}{ Commercial } & \multirow[t]{2}{*}{ Cotton coated with PVC } & RDP & $11.2 \%$ \\
\hline & & & $\mathrm{Sb}_{2} \mathrm{O}_{3}$ & $3.0 \%$ \\
\hline Coating-2 & Commercial & Jersey/PA coated with PVC & $\mathrm{Sb}_{2} \mathrm{O}_{3}$ & $1.9 \%$ \\
\hline \multirow[t]{2}{*}{ Coating-3 } & \multirow[t]{2}{*}{ Commercial } & \multirow[t]{2}{*}{ Knitted cotton coated with PVC/PU } & $\mathrm{RDP}$ & \multirow[t]{2}{*}{$25 \%$ overall (see text) } \\
\hline & & & TCIPP & \\
\hline \multirow{2}{*}{ Coating-4 } & \multirow{2}{*}{ Commercial } & \multirow{2}{*}{ PET coated with PU } & Brominated FR & $10.5 \%$ (in $\mathrm{Br}$ ) \\
\hline & & & $\mathrm{Sb}_{2} \mathrm{O}_{3}$ & $4.4 \%$ \\
\hline \multirow[t]{2}{*}{ B-Coating } & \multirow[t]{2}{*}{ Commercial } & \multirow[t]{2}{*}{ Polyester } & DBDPE & $25 \%$ \\
\hline & & & $\mathrm{Sb}_{2} \mathrm{O}_{3}$ & $9 \%$ \\
\hline Graft-1 & Commercial & Cotton/PE & THPC & $18 \%$ \\
\hline Graft-2 & Commercial & Cotton & DMPPA & $17 \%$ \\
\hline Graft-3 & Commercial & Cotton & $\mathrm{PA} / \mathrm{GP}$ & $15 \%$ \\
\hline Film-1 & Synthetic & Polyamide (PA) & Melamine pyrophosphate (MP) & $10 \%$ \\
\hline Film-2 & Synthetic & Polypropylene (PP) & Decabromodiphenyl ethane/Antimony trioxide (DBDPE/ $\mathrm{Sb}_{2} \mathrm{O}_{3} 3 / 1$ ) & $10 \%$ \\
\hline Film-3 & Synthetic & Polyethylene terephthalate (PET) & Tetraphenyl resorcinol (RDP) & $10 \%$ \\
\hline
\end{tabular}

subtracting the concentration obtained with a blank solution after treatment of the sweat simulant in the same conditions without any polymer sample. The ability of FRs to migrate in artificial sweat was quantitatively evaluated for all the substances except DBDPE, which is not soluble enough to guarantee the reliable calibration of an analytical method. The results are expressed both as the absolute amount of FR emitted in the sweat per area unit of the sample $\left(\mathrm{mg} / \mathrm{dm}^{2}\right)$ and as the corresponding calculated proportion of the FR initially present in the matrix.

\section{Results and discussion}

\subsection{Identification of the most relevant $F R /$ matrix combinations}

A comprehensive review of the literature (research papers) has identified nearly a hundred substances used indifferently in the fireproof treatment of several materials, including foams and coatings used in UF. This review was complemented by an extensive review of institutional reports [2, 23, 24, 25, and 26] as well as by surveys of representatives of FRs manufacturers (including GTFI (French technical group against fire) and EFRA (European Association of Flame Retarders)). All the identified 22 substances are considered to be the most frequently used in UF (approximately 80\%) (Table 2). Although in some samples it was not possible to determine with certainty the FRs used, the nature of the FR (if present) and its relative quantity in the different samples could be determined with confidence in most cases (Table 1). The analysis focused on the coating layer of the samples, as the nature of the fabric was given by the supplier. First of all, ESEM observation revealed that all the coated cloths were coated with two different layers, a thick inner layer and a thin outer layer, the latter presumably corresponding to a surface treatment (Fig. 1). As this layer was very thin (a few $\mu \mathrm{m}$ only), it could not be analysed with precision. Only qualitative information could be gathered on the nature of the layer (polyvinyl chloride (PVC) and/or PU in general) and on the possible incorporation of substances containing elements that were not present in the thick layer (such as fluorine in the case of anti-staining treatment). When phosphorus (P) was detected, suggesting the incorporation of an organophosphate FR, phosphorus was also found in the thick layer. The results given below for the coatings were therefore obtained from the thick layer (Fig. 1).

Three coatings (Coating-1, Coating-2 and Coating-3, Fig. 1) were
Table 2

FR substances or synergists and UF materials (matrix).

\begin{tabular}{|c|c|c|c|}
\hline $\begin{array}{l}\text { Role of } \\
\text { substances }\end{array}$ & Substance & Matrix & $\begin{array}{l}\text { Method of } \\
\text { incorporation }\end{array}$ \\
\hline \multirow[t]{19}{*}{ FRs } & TMPP & Foam, PVC & Recovery \\
\hline & TCIPP & Foam & Additive \\
\hline & TDCPP & Foam & Additive \\
\hline & TPHP & Foam & Additive \\
\hline & BEH-TEBP & Foam & Additive \\
\hline & V6 & Foam & Additive \\
\hline & DBDPE & Fabric, polyester, & Back coating \\
\hline & MP & leather & Recovery \\
\hline & $\mathrm{RDP}$ & Synthetic fabric & Back coating \\
\hline & HBCDD & Polyester & Back coating \\
\hline & M & Synthetic fabric & Additive \\
\hline & BAPP & Foam & Back coating \\
\hline & DecaBDE & Fabric, polyester & Back coating \\
\hline & IPTPP & Fabric, polyester, & Recovery \\
\hline & DMPPA & leather & Grafting \\
\hline & GP & Foam, PVC & Grafting \\
\hline & THPC & Cotton & Grafting \\
\hline & & Cotton & \\
\hline & & Cotton & \\
\hline \multirow[t]{5}{*}{ Synergists } & PHFZ & Wool & Additive \\
\hline & $\mathrm{Sb}_{2} \mathrm{O}_{3}$ & Polypropylene & Back coating \\
\hline & $\mathrm{ZrAC}$ & Wool & Additive \\
\hline & OPA & Cotton & Grafting \\
\hline & $\mathrm{PA}$ & Polyester & Grafting \\
\hline
\end{tabular}

BEH-TEBP: Bis-(2-ethylhexyl) tetrabromophthalate; M: Melamine; HBCDD: Hexabromocyclododecane; BAPP: Bisphenol A Bis-(diphenyl phosphate); DBDPE: Decabromodiphenyl Ethane; DecaBDE: Decabromodiphenyl ether; IPTPP: Tris(4-isopropylphenyl) phosphate; DMPPA: 3-(Dimethylphosphono)-Nmethylolpropionamide; GP: Guanidine phosphate; THPC: Tetrakis(hydroxymethyl)phosphonium chloride; PHFZ: Potassium hexafluorozirconate; ZrAc: Zirconium acetate; OPA: Orthophosphoric acid; PA: Phosphinic acid.

found to be mostly composed of PVC, which was easily detected due to its high chlorine content (PVC contains $56 \%(\mathrm{w} / \mathrm{w})$ chlorine). The fourth coating (Coating-4) was identified as PU at the laboratory by several analytical methods. In the Coating- 1 and Coating- 2 samples, the $\mathrm{PVC}$ coating layer also contained $\mathrm{Sb}$. The presence of $\mathrm{Sb}$ was attributed to the incorporation of $\mathrm{Sb}_{2} \mathrm{O}_{3}$. In the Coating-1 sample, $\mathrm{P}$ was also detected. The exact nature of the P-containing substance was only determined later after the implementation of migration studies, as RDP 

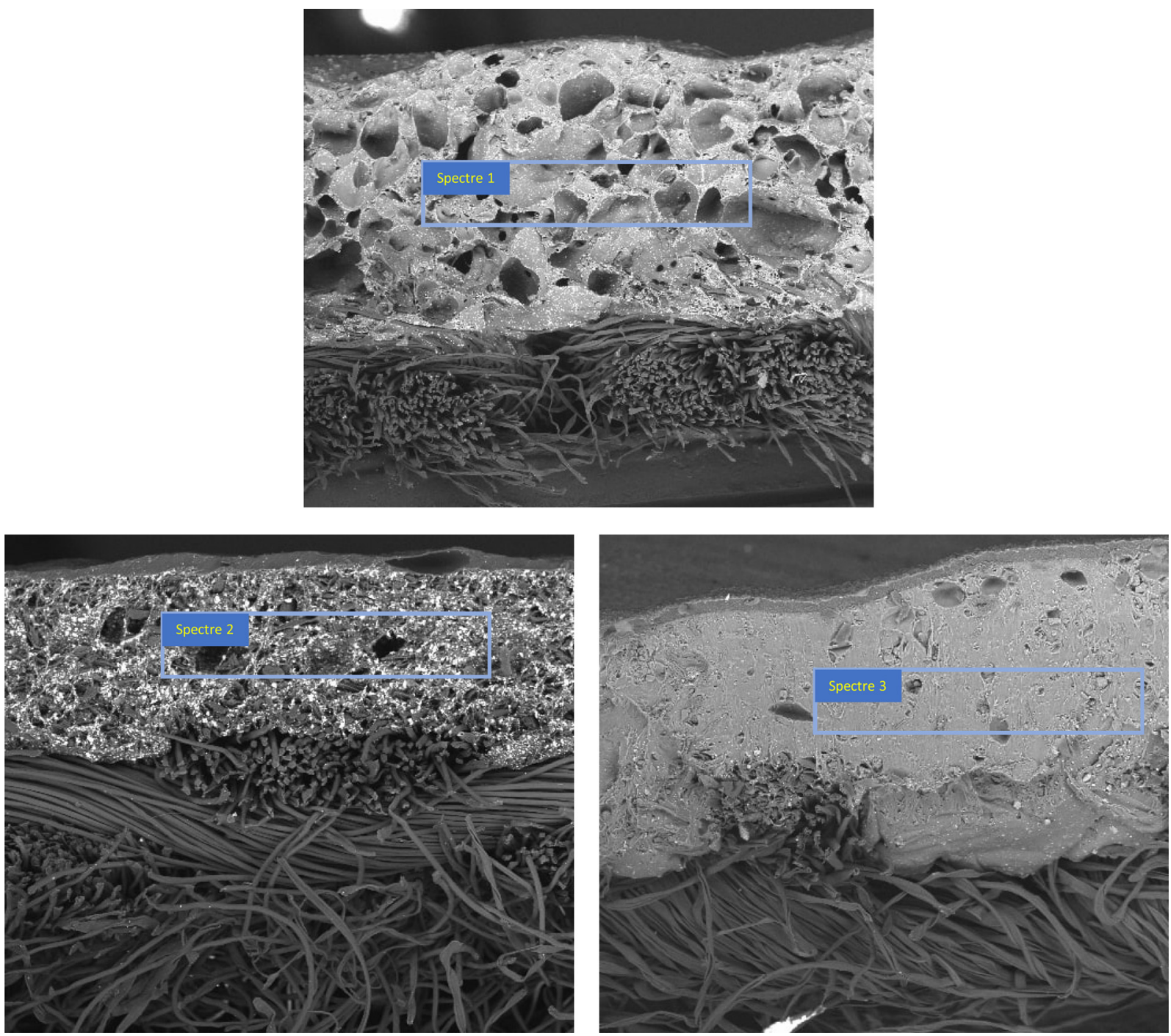

Fig. 1. ESEM view of a cross-section of the Coating-1, Coating-2 and Coating-3 sample (Box: area of analysis).

was found in the sweat simulant. The Coating-2 sample did not contain any other element characteristic of the previously mentioned FR; it is likely that this coating enables UF to pass fire-resistance tests without the addition of a specific FR. Depending on their structure (density), some of the polymers used in UF manufacture are intrinsically fire-resistant. The third sample containing a PVC coating (Coating-3) did not contain Sb but had a high P content $(2.8 \%, w / w)$. Again, the exact nature of the P-containing substances was determined based on the results of the migration studies and corresponds to a mixture of TCIPP and RDP, albeit in unknown proportions. The last sample (Coating-4) was a PU coating layer, containing a high amount of $\mathrm{Br}(10.5 \%, \mathrm{w} / \mathrm{w})$ and $\mathrm{Sb}(4.4 \%, \mathrm{w} / \mathrm{w}$, thus an approximately $4 / 1 \mathrm{Sb} / \mathrm{Br}$ atomic ratio), suggesting the use of a synergistic mixture containing $\mathrm{Sb}_{2} \mathrm{O}_{3}$ and a brominated FR. The exact nature of the latter could not be determined, even after the migration studies. Further structural investigations on were not attempted. The last coated sample was coated on its back (Bcoating). An analysis of its coated side showed a very high Br content $(21.3 \%, \mathrm{w} / \mathrm{w})$, as well as the presence of $\mathrm{Sb}(7.5 \%, \mathrm{w} / \mathrm{w})$ at a level compatible with the use of a DBDPE $/ \mathrm{Sb}_{2} \mathrm{O}_{3} 3 / 1$ mixture. This ratio corresponds to that usually used, according to the literature analysis presented above.

The analyses of the foam samples (Foam-4, Foam-5, Foam- 6 and Foam-7) all showed the simultaneous presence of $\mathrm{P}$ and $\mathrm{Cl}$, in an atomic ratio close to $1 / 3$. Considering the possible structures of organophosphorus substances, TCIPP appeared as the most likely structure. Tris(2-chloroethyl) phosphate (TCEP) and V6 also contain $\mathrm{Cl}$ and $P$ in a 3/1 ratio, but their use appears highly unlikely because TCEP is now banned from the market and V6 is not used on the European market according to industrial suppliers. The $\mathrm{Cl}$ content varied among the different foam samples, ranging from $0.9 \%$ to $2.9 \%$, corresponding to a TCIPP rate of 3 to $8.7 \%(\mathrm{w} / \mathrm{w})$.

Cotton is also a matrix regularly used in fireproofed UF, and FRs can be grafted by reaction with the free hydroxyl moieties of cellulose. The analysis of the cotton fabrics revealed different $\mathrm{P}, \mathrm{Cl}$ and $\mathrm{N}$ contents, in ratios compatible with THPC $(\mathrm{P} / \mathrm{Cl}=1)$, DMPPA $(\mathrm{P} / \mathrm{N}=1)$ and PA-GP $(\mathrm{P} / \mathrm{N}=1 / 3)$, reagents regularly used in the reactive grafting processes.

The substances identified were highly dependent on the matrix to be treated. As a consequence, it is necessary to consider "matrix/FR" pairs, and to accurately link the FR used with the matrix and the incorporation method (Table 2). A single flame retardant can sometimes be used to treat different matrices. Furthermore, depending on the matrix and/ or FR, the incorporation method may vary (simple addition, grafting, coating). In some cases, the fire-retardant effect can be optimised by adding another synergist chemical. A synergist does not lead to a fireproofing effect by itself but will increase the effect of another FR when used in partial substitution with it. A well-known example consists in the addition of $\mathrm{Sb}_{2} \mathrm{O}_{3}$ to halogenated substances.

To complement these commercial samples, several synthetic 
Table 3

Results of FR migration in artificial sweat.

\begin{tabular}{|c|c|c|c|}
\hline Sample & $\begin{array}{l}\text { FR and amount } \\
\text { (in weight \%) }\end{array}$ & $\begin{array}{l}\text { Quantity of FR migrating } \\
\left(\mathrm{mg} / \mathrm{dm}^{2}\right)\end{array}$ & $\begin{array}{l}\text { Proportion } \\
\text { mobilised }\end{array}$ \\
\hline \multicolumn{4}{|l|}{ FOAM } \\
\hline Foam-1 (*) & TCIPP $8.6 \%$ & $32 \pm 4$ & $7.1 \%$ \\
\hline Foam-2 (*) & TDCPP 8.6\% & $1.6 \pm 0.1$ & $0.4 \%$ \\
\hline Foam-3 $\left(^{*}\right)$ & TPHP 8.6\% & $0.2 \pm 0.05$ & $0.05 \%$ \\
\hline \multicolumn{4}{|l|}{ COATING } \\
\hline \multirow[t]{2}{*}{ Coating-1 $(* *)$} & $\mathrm{Sb}_{2} \mathrm{O}_{3} 3.0 \%$ & $0.008 \pm 0.001(\mathrm{Sb})$ & $<0.01 \%(\mathrm{Sb})$ \\
\hline & RDP $11.2 \%$ & $3.4 \pm 0.2(\mathrm{RDP})$ & $0.5 \%$ (RDP) \\
\hline Coating-2 $(* *)$ & $\mathrm{Sb}_{2} \mathrm{O}_{3} 1.9 \%$ & $0.038 \pm 0.002(\mathrm{Sb})$ & $0.02 \%(\mathrm{Sb})$ \\
\hline \multirow[t]{2}{*}{ Coating-3 $(* *)$} & RDP \& TCIPP & $5.4 \pm 0.1(\mathrm{RDP})$ & - \\
\hline & $25 \%$ & $0.8 \pm 0.01$ (TCIPP) & \\
\hline \multicolumn{4}{|c|}{ BACK COATING } \\
\hline B-Coating (**) & $\begin{array}{l}\text { DBDPE } 25 \% \text {, } \\
\mathrm{Sb}_{2} \mathrm{O}_{3} 9 \%\end{array}$ & $1.3 \pm 0.02(\mathrm{Sb})$ & $0.9 \%(\mathrm{Sb})$ \\
\hline \multicolumn{4}{|l|}{ GRAFTING } \\
\hline Graft-1 $(* *)$ & THPC $18 \%$ & $12.3 \pm 1.6$ & $2.1 \%$ \\
\hline Graft-2 $(* *)$ & DMPPA 17\% & $10.2 \pm 1.6$ & $2 \%$ \\
\hline Graft-3 $(* *)$ & $\mathrm{PA} / \mathrm{GP} 15 \%$ & $48.8 \pm 1.4$ & $34 \%\left(\mathrm{PO}_{4}{ }^{3-}\right)$ \\
\hline \multicolumn{4}{|c|}{ INCORPORATION } \\
\hline Film-1 (*) & MP $10 \%$ & $22.5 \pm 0.1$ (Melamine) & $16 \%$ (Melamine) \\
\hline Film-2 (*) & $\begin{array}{l}\mathrm{DBDPE} / \mathrm{Sb}_{2} \mathrm{O}_{3}(3 / \\
1 \text { mixture }) 10 \%\end{array}$ & $0.003 \pm 0.001(\mathrm{Sb})$ & $<0.01 \%(\mathrm{Sb})$ \\
\hline Film-3 (*) & RDP $10 \%$ & $0.85 \pm 0.04$ & $0.36 \%$ \\
\hline
\end{tabular}

*synthetic sample, **commercial sample, ND: not determined.

samples of known composition have been prepared according to standard methods (Table 1). Preparation of these samples was decided because (i) in the case of foams, only TCIPP was found in commercial samples, whereas other phosphate esters such as TPHP and TDCPP are likely to be found; (ii) coated fabrics result from the association of several different polymers. Thus, for results interpretation, it was considered that more simple samples obtained from one polymer only could be of interest. As a result, a complete set of commercial and synthetic samples was available for migration studies (Table 3 ).

\subsection{Migration studies}

Laboratory-prepared and commercial samples were used for the migration studies. The wide variety of studied samples enabled information to be gathered on different FRs, different preparation processes and different polymer matrices. When present, all compounds were quantified well above the quantification limits (LoQ) of the analytical methods used. The migration results are reported in Table 3.

When they were incorporated into the same matrix (PU foam), TCIPP, TDCPP and TPHP showed different abilities to migrate into the sweat simulant. The proportion of FR found in the sweat simulant was highest for TCIPP (7.1\%), followed by TDCPP (0.4\%), and was lowest for TPHP $(0.05 \%)$. This order was the same that of the substances' hydrophobicity, reflected by their octanol/water partition coefficient (Pow) (TCIPP, $\log$ Pow = -3.04; TDCPP, $\log$ Pow $=3.69$; and TPHP, $\log$ Pow $=4.6)$.

When antimony trioxide $\left(\mathrm{Sb}_{2} \mathrm{O}_{3}\right)$ was incorporated into a rigid polymer matrix, its migration into artificial sweat was very low (maximum $0.02 \%(\mathrm{Sb})$ in a coated PVC coating, Table 3). However, when $\mathrm{Sb}_{2} \mathrm{O}_{3}$ was embedded in the coating on the back side of a fabric (Table 3), the concentration of Sb found in the synthetic sweat after the migration test was much higher, and the proportion of $\mathrm{Sb}_{2} \mathrm{O}_{3}$ mobilised into the synthetic sweat reached $0.9 \%$. This major difference cannot be simply attributed to different $\mathrm{Sb}_{2} \mathrm{O}_{3}$ incorporation rates: the method of incorporation appeared as the most significant parameter.

THPC and DMPPA were incorporated into the same matrix (cotton fabric) by similar grafting processes. The migration rates for THPC and DMPPA were not significantly different and were close to $11 \mathrm{mg} / \mathrm{dm}^{2}$ (corresponding to around $2 \%$ of the initial FR load). It appeared that grafting did not entirely prevent the migration of FRs, as both molecules were found in the sweat simulant (Table 3). This behaviour may result from incomplete grafting of the substances. We could not investigate the influence of the grafting process and did not attempt to characterise the residual monomers present in the cotton samples.

Migration of the phosphate ion from the PA-GP FR combination was found to be very high (34\% of the initial load of phosphate ion could migrate, Table 3), much more than that of THPC and DMPPA incorporated into the same matrix. The high migration of the phosphate ion from the PA-GP pair can be attributed to the higher hydrophilicity of the FR (log Pow $=-1.26$ ) and a different grafting process.

Melamine was the substance that showed the highest potential to migrate from a synthetic film with a mobilised proportion representing $16 \%$ of its initial amount in the polymer matrix (Table 3). Migration of $\mathrm{Sb}_{2} \mathrm{O}_{3}$ incorporated into a rigid polymer matrix was very low $(<0.01 \%$ in a polypropylene film) compared to commercial samples (Table 3 ). The same trend was also observed with RDP, although direct comparison with commercial samples (Table 3 ) is not possible.

The results showed that the nature of the matrix/FR pair significantly impacts the migration process and that the most hydrophilic substances are more prone to migration (e.g. TCIPP). Nonetheless, it cannot be ruled out that poorly hydrophilic substances may also readily migrate, depending on the structure of the treated materials. The method of incorporating the FR does not appear to guarantee complete immobilisation within the matrix. As a result, migration was also observed for FRs grafted onto the polymer matrix, even though this technique supposedly prevents any subsequent release of the substance. In this case, the low proportion of FR that migrates could correspond to residual monomers that were not incorporated into the matrix during grafting or to monomers released during the ageing of the matrix.

The protocol used in this study enabled a comparison of FRs from the same family embedded in similar materials as well as a comparison of various techniques of FR incorporation (grafting, addition in the polymer, coating). A relationship between hydrophilicity and migration potential was first expected and then clearly demonstrated for phosphate esters TCIPP, TDCPP and TPHP embedded in PU foams. More intriguing were the results obtained with $\mathrm{Sb}_{2} \mathrm{O}_{3}$ and grafted FRs: both categories of FRs had so far been regarded as rather inert. It was indeed assumed that inorganic salt or a grafted organic substance could escape from the matrix. Although we were not able to establish whether the migration of THPC and DMPPA was the result of the presence of residual monomers or of the breaking of the covalent bond in the matrix; our experiments demonstrated that exposure to these substances is possible after skin contact with the UF and should be considered a potential risk. No additional migration cycles were tested on the same surface and no diffusion of the substances inside the material was considered; the effects of repeated exposure could not be assessed.

\subsection{Potential benefits and associated risks}

The causes of household fires are highly variable and unknown in numerous cases. They include lit cigarettes and electrical or gas failures [1]. The use of battery-powered smoke alarms, the presence of smoke detectors/alarms, housing characteristics, and the social profile of the occupant populations may also play a role in triggering and detecting a fire, and must therefore be taken into account. It is therefore almost impossible to determine the potential safety benefits of using FRs in UF [1]. To reduce the flammability of UF and the number of fires in homes, fire resistance tests have been developed and made mandatory in some countries. FRs may therefore be used by industry to pass these tests. The complete fireproofing of UF can be complex, as it may contain multiple layers and coatings with different FRs: The fireproofing of UF does not necessarily rely on foam treatment, and solutions based on the set-up of a barrier layer or fireproofing of the fabric are also proposed.

All the identified substances are registered under the REACH 
Regulation, except GP, MP, and BAPP. For substances registered under tonnage bands of 100-1000 tonnes/year (ZrAc, PA, PHFZ, DMPPA, BEH-TEBP, V6, and OPA), the provided data on toxicity are usually limited to repeated-dose studies either after sub-acute (28-day) and/or sub-chronic (90-day) exposure (for some substances, these data may be waived by the applicants, based on appropriate justification), reprotoxicity studies for one species (fertility and development), and in vitro genotoxicity tests. For substances registered for more than 1000 tonnes/year (IPTPP, DBDPE, DecaBDE, HBCDD, THPC, and $\mathrm{Sb}_{2} \mathrm{O}_{3}$ ), chronic toxicity and carcinogenicity studies are generally assessed based on animal studies and/or read-across analyses. Six of these substances benefit from a harmonised classification according to Annex VI of the CLP Regulation (Table S2). Regarding the substances not registered under the REACH Regulation, the data for GP and MP are practically non-existent and for BAPP, the sparse data were provided by the Australian National Industrial Chemicals Notification and Assessment Scheme (NICNAS) and summarised by the US-EPA [24]. In addition, HBCDD was added to the list of persistent organic pollutants (POPs) in Annex A (Stockholm Convention, 24 April to 5 May 2017). DecaBDE is considered a substance of very high concern (SVHC) and has been included in the candidate list for authorisation, and some of its uses are restricted under Annex XVII of REACH.

Several FRs are considered potentially carcinogenic to humans. TDCPP and $\mathrm{Sb}_{2} \mathrm{O}_{3}$ are classified in carcinogen category 2 (ATP 03) according to the CLP Regulation. Moreover, the US-EPA [24] considers DecaBDE a potential human carcinogen and does not rule out the possibility of TBPE being so. Concerning V6, the US-EPA [24] considers that the risk of carcinogenicity was moderate. Regarding TCIPP, and based on the results of an unpublished 13-week animal study, European experts $[27,28]$ concluded that some of the observed effects might progress towards carcinogenicity through a non-genotoxic mechanism. Lastly, concerning DBDPE, even though there are no carcinogenicity data, its carcinogenic potential should be considered because of its structural similarity to DecaBDE [24]. THPC appears to have a promoter effect on skin tumours [29] while certain FRs may demonstrate reproductive toxicity. This is specifically the case for HBCDD, BEHTEBP and TMPP, which are classified as reprotoxic substances of category 2 (ATP 03) according to the CLP Regulation, as well as for BEHTEBP and melamine, for which reprotoxic effects have been reported [30-32].

Finally, some FRs such as TPHP are suspected to be potential endocrine-disrupters and other such as DecaBDE, DBDPE or IPTPP are suspected to be developmental neurotoxicant $[24,26]$. Other FRs have the thyroid as the target organ. For example, an increase in thyroid weight, along with histo-pathological changes, was observed following exposure to V6 in a two-generation study [27,28]. Effects on thyroid were also reported in several studies with HBCDD [33-35].

Aside from their human toxicity, the FRs identified in this study may have effects on the environment. Some FRs, like TDCPP and HBCDD, show high chronic and acute ecotoxicity [26,34]. Some FRs do not readily degrade and therefore persist in the environment, as is the case for TCIPP, HBCDD, DBDPE, BAPP, TMPP, IPTPP and $\mathrm{Sb}_{2} \mathrm{O}_{3}$ [24,26]. In addition, BEH-TEBP generates metabolites and degradation products that persist in the environment [26].

\section{Conclusion}

In this study, FR migration was investigated using matrices taken from commercial outlets and reconstituted laboratory samples.

As a study migration of FRs used in UF had not been conducted so far, an experimental set-up was designed in order to assess the possible Human exposure to FRs incorporated in UF through skin contact, mediated by sweat.

Our results of FR migration complement the already available literature data regarding exposure via inhalation. Those results had shown that some phosphorus FRs can be emitted into the air, leading to a potential risk of exposure by inhalation. Finally, those results demonstrate that it is difficult to clearly identify an inert FR substance, both in terms of emission and migration, regardless of the type of FR used.

Those results had shown that some phosphorus FRs can be emitted into the air, leading to a potential risk of exposure by inhalation.

There is a clear lack of quantitative data on the effects on health and on the environment of the 22 substances identified in this study as the most commonly used in UF. That is why, it was not possible to assess a benefit/risk ratio that could justify generalising the flame-retardant treatment of UF. For most of these 22 substances, data, when available, suggest potential adverse effects on human health including reprotoxicity, endocrine disruption, carcinogenicity, neurotoxicity. Moreover, these substances may also have impacts on the environment due to their ecotoxicity, persistence or bioaccumulation. Otherwise, it should be noted that improved reaction towards fire could be achieved with techniques other than FR embedding. This explains why the authors consider that the use of FRs in domestic upholstery does not seem to be justified due to potential risks and a lack of clear benefits. ANSES recommended that the use of FRs in domestic UF should not be generalised since safe alternatives are available. Finally, our results suggest that migration studies should be performed in a more systematic way before concluding on the safe use of newly proposed FRs incorporated into polymer materials.

\section{Acknowledgements}

We are grateful to the ANSES Expert Committee (CES) on "Assessment of the chemical risks of consumer items and products" that has conducted and validated this work.

\section{Appendix A. Supplementary data}

Supplementary material related to this article can be found, in the online version, at doi:https://doi.org/10.1016/j.jhazmat.2018.11.110.

\section{References}

[1] ANSES, Evaluation des risques liés à l'exposition aux retardateurs de flamme dans les meubles rembourrés - Partie 1: Efficacité contre le risque d'incendie des retardateurs de flamme dans les meubles rembourrés, (2014) https://www.anses.fr/ fr/system/files/SUBCHIM2011sa0132Ra-01.pdf.

[2] ARCADIS, Evaluation of Data on Flame Retardants in Consumer Products. Final Report, (2011) http://ec.europa.eu/consumers/safety/news/flame_retardant_ substances_study_en.pdf.

[3] V. Babrauskas, A. Blum, R. Daley, L. Birnbaum, Flame retardants in furniture foam: benefits and risks, Fire Saf. Sci. 10 (2011) 265-278, https://doi.org/10.3801/ IAFSS.FSS.10-265.

[4] C. Chivas, E. Guillaume, A. Sainrat, V. Barbosa, Assessment of risks and benefits in the use of flame retardants in upholstered furniture in continental Europe, Fire Saf. J. 44 (2009) 801-807.

[5] J.L. Lyche, C. Rosseland, G. Berge, A. Polder, Human health risk associated with brominated flame-retardants (BFRs), Environ. Int. 74 (2015) 170-180.

[6] H. Fromme, G. Becher, B. Hilger, W. Völkel, Brominated flame retardants - exposure and risk assessment for the general population, Int. J. Hyg. Environ. Health 219 (2016) 1-23.

[7] N. Kajiwara, Y. Noma, H. Takigami, Brominated and organophosphate flame retardants in selected consumer products on the Japanese market in 2008, J. Hazard. Mater. 192 (2011) 1250-1259.

[8] M. Zhanga, A. Buekens, X. Li, Brominated flame retardants and the formation of dioxins and furans in fires and combustion, J. Hazard. Mater. 304 (2016) 26-39.

[9] S.T. McKenna, R. Birtles, K. Dickens, R.G. Walker, M.J. Spearpoint, A.A. Stec, T.R. Hull, Flame retardants in UK furniture increase smoke toxicity more than they reduce fire growth rate, Chemosphere 196 (2018) 429-439.

[10] H.M. Stapleton, S. Klosterhauss, S. Eagle, J. Fuh, J.D. Meeker, A. Blum, T.F. Webster, Detection of organophosphate flame retardants in furniture foam and U.S. House dust, Environ. Sci. Technol. 43 (2009) 7490-7495.

[11] S.J. Chen, Y.J. Ma, J. Wang, M. Tian, X.J. Luo, D. Chen, B.X. Mai, Measurement and human exposure assessment of brominated flame retardants in household products from South China, J. Hazard. Mater. 176 (2010) 979-984.

[12] H.M. Stapleton, S. Klosterhaus, A. Keller, P.L. Ferguson, S. van Bergen, E. Cooper, T.F. Webster, A. Blum, Identification of flame retardants in polyurethane foam collected from baby products, Environ. Sci. Technol. 45 (2011) 5323-5331.

[13] N. Ali, S. Harrad, E. Goosey, H. Neels, A. Covaci, "Novel" brominated flame 
retardants in Belgian and UK indoor dust: implications for human exposure, Chemosphere 83 (2011) 1360-1365.

[14] N. Ali, A.C. Dirtu, N. Van den Eede, E. Goosey, S. Harrad, H. Neels, A. Mannetje, J. Coakley, J. Douwes, A. Covaci, Occurrence of alternative flame retardants in indoor dust from New Zealand: indoor sources and human exposure assessment, Chemosphere 88 (2012) 1276-1282.

[15] T.G. Cleary, T.J. Ohlemiller, K. Villa, The influence of ignition source on the flaming fire hazard of upholstered furniture, Fire Saf. J. 13 (1994) 79-102.

[16] C. Jiao, H. Wang, S. Li, X. Chen, Fire hazard reduction of hollow glass microspheres in thermoplastic polyurethane composites, J. Hazard. Mater. 332 (2017) 176-184.

[17] X. Chen, W. Wang, S. Li, C. Jiao, Fire safety improvement of para-aramid fiber in thermoplastic polyurethane elastomer, J. Hazard. Mater. 324 (2017) 789-796.

[18] A. Reynier, P. Dole, A. Feigenbaum, Prediction of worst case migration: presentation of a rigorous methodology, Food Addit. Contam. 16 (1999) 137-152.

[19] P. Dole, A.E. Feigenbaum, C. De La Cruz, S. Pastorelli, P. Paseiro, T. Hankemeier, Y. Voulzatis, S. Aucejo, P. Saillard, C. Papaspyrides, Typical diffusion behaviour in packaging polymers - application to functional barriers, Food Addit. Contam. 23 (2006) 202-211.

[20] M. Ghislain, J. Beigbeder, L. Dumazert, J.M. Lopez-Cuesta, M. Lounis, S. Leconte V. Desauziers, Determination of the volatile fraction of phosphorus flame retardants in cushioning foam of upholstered furniture: towards respiratory exposure assessment, Environ. Monit. Assess. 188 (2016) 576, https://doi.org/10.1007/s10661016-5566-y.

[21] S. Kemmlein, O. Hahn, O. Jann, Emissions of organophosphate and brominated flame retardants from selected consumer products and building materials, Atmos. Environ. 37 (2003) 5485-5493.

[22] J.N. Hahladakis, C.A. Velis, R. Weberb, E. Iacovidou, P. Purnell, An overview of chemical additives present in plastics: migration, release, fate and environmental impact during their use, disposal and recycling, J. Hazard. Mater. 344 (2018) 179-199.

[23] LNE, Etude sur les effets de l'ignifugation de certains meubles rembourrés dans le cadre d'un projet de réglementation relative à la sécurité incendie. Fiche 233/2007, (2008) https://portail.itech.fr/pmb/opac_css/index.php?lvl = notice_display\&id= 21277.

[24] US-EPA, An Alternatives Assessment for the Flame Retardant Decabromodiphenyl Ether (DecaBDE). Final Report, U.S. Environmental Protection Agency), 2014, https://www.epa.gov/sites/production/files/2014-05/documents/decabde_final. pdf.

[25] US-EPA, Flame Retardants Used in Flexible Polyurethane Foam: an Alternatives Assessment Update, U.S. Environmental Protection Agency), 2014.

[26] US-EPA, Flame Retardants Alternatives for Hexabromocyclododecane (HBCDD). Final Report, U.S. Environmental Protection Agency), 2014.

[27] EU-RAR, Tris [2-chloro-1-methyl) Phosphate (TCIPP), European Union Risk Assessment Report, 2008, https://echa.europa.eu/documents/10162/13630/trd rar_ireland_tccp_en.pdf.

[28] EU-RAR, 2,2-Bis(Chloromethyl) Trimethylene Bis[bis(2-chloroethyl)phosphate] (v6). Fire Safety Science-proceedings of the Tenth International Symposium: 265278, European Union Risk Assessment Report, 2008, https://echa.europa.eu/ documents/10162/9e03b67c-8a0b-4de7-814e-a8a4ec63b9ae.

[29] G. Loewengart, B.L. Van Duuren, Evaluation of chemical flame retardants for carcinogenic potential, J. Toxicol. Environ. Health 2 (1977) 539-546.

[30] C. Springer, E. Dere, S.J. Hall, E.V. McDonnell, S.C. Roberts, C.M. Butt, H.M. Stapleton, D.J. Watkins, M.D. McClean, T.F. Webster, J.J. Schlezinger, $\mathrm{K}$. Boekelheide, Rodent thyroid, liver, and foetal testis toxicity of the monoester metabolite of bis-(2-ethylhexyl) tetrabromophthalate (BEH-TEBP), a novel brominated flame retardant present in indoor dust, Environ. Health Perspect. 120 (2012) 1711-1719 https://ehp.niehs.nih.gov/wp-content/uploads/120/12/ehp.1204932. pdf.

[31] H.B. Patisaul, S.C. Roberts, N. Mabrey, K.A. McCaffrey, R.B. Gear, J. Braun, S.M. Belcher, H.M. Stapleton, Accumulation and endocrine disrupting effects of the flame retardant mixture Firemaster 550 in rats: an exploratory assessment, J. Biochem. Mol. Toxicol. 27 (2013) 124-136.

[32] R.H. Yin, X.Z. Wang, W.L. Bai, The reproductive toxicity of melamine in the absence and presence of cyanuric acid in male mice, Res. Vet. Sci. 94 (2013) 618-627.

[33] H. Zeller, P. Kirsch, Hexabromocyclododecane: 28-day Feeding Trials with Rats, BASF, 1969 Unpublished laboratory report.

[34] M. Ema, S. Fujii, M. Hirata-Koizumi, M. Matsumoto, Two-generation reproductive toxicity study of the flame retardant hexabromocyclododecane in rats, Reprod. Toxicol. 25 (2008) 335-351.

[35] Y. Saegusa, H. Fujimoto, G.H. Woo, K. Inoue, M. Takahashi, K. Mitsumori, M. Hirose, A. Nishikawa, M. Shibutani, Developmental toxicity of brominated flame retardants, tetrabromobisphenol A and 1,2,5,6,9,10-hexabromocyclododecane, in rat offspring after maternal exposure from mid-gestation through lactation, Reprod. Toxicol. 28 (2009) 456-467. 